\title{
Elektrik Dağıtım Şebekelerinde Kendi Kendini İyileştiren Sistemler
}

\author{
Gökmen HASANÇEBİ ${ }^{1}$, Erdal Mustafa YEĞİN ${ }^{2}$, Korhan KARAARSLAN ${ }^{2 *}$ \\ ${ }^{I}$ SEDASS İl İsletme Müdürlüğü, 41400, Kocaeli \\ ${ }^{2}$ Kocaeli Üniversite, Mühendislik Fakültesi, Elektrik Mühendisliği Bölümü, 41380, Kocaeli \\ (ORCID: 0000-0002-2799-3052) (ORCID: 0000-0002-1665-3132) (ORCID: 0000-0001-7109-3636)
}

\begin{abstract}
$\ddot{O} \mathbf{z}$
Kaçınılmaz sanayileşme ve günlük hayattaki dijitalleşmeye olan hızlı eğilim nedeniyle elektrik enerjisine bağımlılık günden güne artmaktadır. Bu sebeple, tüketiciye enerji tedariğini gerçekleştiren elektrik dağıtım şebekelerinin kalitesi, erişilebilirliği ve güvenilirliği üzerinde durulması gereken önemli bir konu başlığıdır. Konvansiyonel dağıtım şebekelerinde kullanılmakta olan kesinti yönetimi süreçleri bu doğrultuda, kesinti sürelerini minimize edecek şekilde güncellenmekte ve dağıtım otomasyonu sistemleri ile kendi kendini iyileştiren şebekelere geçiş çalışmaları yapılmaktadır. Yurt dışında konsept doğrulama çalışmaları farklı topolojiler ile devam etmekte olan kendi kendini iyileştiren şebekeler henüz pilot uygulama seviyesindedir ve bu alanla ilgili Türkiye'deki ilk adımı Sakarya Elektrik Dağııım Şirketi (SEDAŞ) atmıştır. SEDAŞ bu amaçla, mevcut otomasyon işlevselliklerini güçlendirerek tedarik sürekliliğini en yüksek seviyeye çıkarmayı hedefleyen kendi kendini iyileştiren şebeke tasarımı ve uygulama projesini başlatmıştır. Bu çalışmada, söz konusu proje kapsamında yapılan çalışmalardan elde edilen kazanımlar doğrultusunda gerçekleştirilen geniş alanlı otonom dağıtım şebekesi tasarım kriterleri, otonom sisteme dahil edilecek olan şebeke unsurlarının seçimi, sistem için gerekli otomasyon ekipmanlarının minimum teknik gereklilikleri ve SEDAŞ sorumluluk alanında seçilen pilot bölge için yapılan tasarım anlatılmıştır. Müşteri başına düşen kesinti süresi teorik olarak uygulama öncesi durum ve uygulama sonrası durum için hesaplanarak kesinti sürelerinde öngörülen iyileştirme oranı belirlenmiştir. Bununla birlikte, olası yeniden enerjilendirme manevraları için şebekedeki akım taşıma kapasitesi, gerilim düşümü gibi teknik parametreler de dikkate alınmıştır.
\end{abstract}

Anahtar kelimeler: Kendi kendini iyileştiren şebekeler, Akıllı şebekeler, Dağıtım sistemi, Arıza izolasyonu, Güvenilirlik, SCADA.

\section{Self-healing Systems for Electrical Distribution Networks}

\begin{abstract}
Due to the inevitable industrialization and the rapid trend towards digitalization in daily life, the electrical energy dependence is increasing day by day. For this reason, the quality, availability and reliability of the electrical distribution networks that supply energy to the consumers is an important issue. Fault management processes used in conventional distribution networks are updated in such a way to minimize the interruption duration and, transition studies are carried out to self-healing systems through distribution automation systems. Self-healing systems are under test in pilot scheme of which conceptual validation studies are performed with different architectures. The first self-healing system design and implementation project in Turkey was initiated by Sakarya Electricity Distribution Company (SEDAS) aiming to maximize supply continuity by strengthening existing automation functionality. In this study, the design of the autonomous distribution network design criteria, the selection of the network elements to be included in the autonomous system, the minimum technical requirements of the automation equipment required for the system and the design for the selected pilot region in the responsibility area of SEDAS are explained. The interruption duration per customer is theoretically calculated for the pre-application and the post-application situations and the improvement in the interruption duration is determined. Furthermore, technical parameters such as ampacity and voltage drop in the network are also taken into account for possible re-energizing maneuvers.
\end{abstract}

Keywords: Self-healing networks, Smart grids, Distribution system, Fault isolation, Reliability, SCADA. 


\section{Giriş}

Kullanıcıların güvenli, kaliteli, güvenilir elektrik enerjisine sürdürülebilir erişimini sağlayabilmeleri için ulusal ve uluslararası alanda çeşitli iyileştirme ve Ar-Ge çalışmaları yapılmaktadır. Mevcut çalışmalar arasında, şebeke işletiminde kullanılan merkezi denetim-veri toplama, dağıtım ve kesinti yönetim sistemlerinin (SCADA/DMS-OMS) gelişmişlik seviyelerini yükseltmek ve günlük sistem operasyonlarını hızlandırmak çok büyük bir öneme sahiptir. Bu amaçla, kendi kendini iyileştiren şebeke mimarileri kullanılarak günlük operasyonlar içerisinde güç sisteminde meydana gelen arızalar nedeniyle oluşan kesintilerin hızlı bir şekilde sistemden izole edilmesi hedeflenmektedir.

Mevcut durumda, SCADA/DMS-OMS yazılımları ile dağıtım şebekesinde bulunan kesici, yük ayırıcıs1 vb. gibi anahtarlar uzaktan kontrol edilebilmektedir. Böylece, arızalara karşı şebekenin topolojisi değiştirilerek sağliklı fiderlerde bulunan müşterilere yeniden enerji sağlanabilmektedir. SCADA operatörleri tarafindan manuel yöntemler ile gerçekleştirilen bu manevralar; anahtarlama işlemlerinin ancak 10-15 dk gibi bir sürede tamamlanabilmesi, topolojik değiş̧iklik sırasında personelin hata yapabilme riski ve personelin şebeke modeli konusunda uzmanlaşma zorunluluğu gibi çeşitli olumsuzluklar barındırmaktadır. Belirtilen dezavantajları minimize etmek için kendi kendini iyileştirebilen şebeke mimarisi (self-healing system) geliştirilmiştir.

Kendi kendini iyileştiren şebeke mimarisinin ilk temelleri, 1999 yılında Elektrik Enerjisi Araştırma Enstitüsü (EPRI) bünyesinde kurulan Kompleks İnteraktif Şebekeler/Sistemler Girişim (CIN/SI) grubu tarafindan atılmıştır. Konsept, yaklaşık 20 senelik bir geçmişe sahip olmasına rağmen otonom sistemlerin yüksek maliyetleri, kalifiye personele gereksinim duymaları ve güvenlik endişeleri nedenleriyle bu tür sistemlerin uygulamaları henüz yaygınlaşmamıştır.

Hollanda'da faaliyet gösteren bir dağıtım sistemi operatörü, $23 \mathrm{kV}$ gerilim seviyesindeki 33 adet dağıtım merkezini kapsayan yer altı kablo şebekesinde otonom arıza izolasyonu ve yeniden enerjilendirme projesini 2012 yılında devreye almıştır [1-2]. Benzer şekilde, İspanya'da hizmet veren bir başka dağıtım sistemi operatörü ise mevcut SCADA/DMS'e otomatik şebeke kurtarma modülü ekleyerek yazılım geliştirmesi yapmıştır. Bu modül aracılığıyla şebekenin büyük bir kısmında otonom restorasyon yapılması mümkün kılınmıştır [3]. Bunun yanında, ABD Enerji Bakanlığı tarafindan sağlanan Akıllı Şebeke Yatırım Fonu üzerinden dağıtım şirketleri yedi adet kendi kendini iyileştiren şebeke projesi yürütmüştür. Saha uygulamaları 2011 ila 2014 yılları arasında tamamlanmış olan bu projelerde kesintiden etkilenen kullanıcı sayısı ve toplam kesinti süresi parametreleri sirasıyla $\% 45$ ve $\% 51$ oranlarında azaltılmıştır [4]. Bu uygulamalara ek olarak, haberleşme performansını ve sistem güvenilirliğini optimize etmek amacıyla bir arıza izolasyonu ve yeniden enerjilendirme kontrol şeması önerilmiştir [5]. Benzer bir kontrol şeması, Mısır'da orta gerilim seviyesindeki şebekede uygulanmak üzere tasarlanmıştır. Monte Carlo benzetim metodu tabanlı yapılan güvenilirlik değerlendirmesinde sistem ortalama kesinti süresi endeksinin (SAIDI) \%32 azaldığı tespit edilmiştir [6].

Türkiye'de ise; Enerji Piyasası Düzenleme Kurumu (EPDK) tarafindan sağlanan Ar-Ge fonu ile SEDAŞ "Kendi Kendini İyileştiren Şebeke" projesini başlatmıştır. Proje, farklı sistem mimarileri ile otonom şebeke tasarımlarını geliştirmeyi ve uygulamayı hedeflemektedir.

$\mathrm{Bu}$ çalışmada, söz konusu proje kapsamındaki çalışmalardan yola çıkarak farklı sistem mimarileri için yapılan değerlendirme ve SEDAŞ sorumluluk alanı içerisindeki pilot bir bölge için durum analizi ayrıntılı bir şekilde anlatılmaktadır. İkinci bölümde, kendi kendini iyileştiren şebekede arıza yönetim sürecine değinilmektedir. Bir arıza oluşması durumunda, otonom sistemin çalışma evreleri ayrıntılı olarak gösterilmektedir. Konvansiyonel arıza yönetim sistemi ile otonom sistemin kesinti sürelerine dair bir karşılaştırma yapılmaktadır. Karar alma noktasının konumu dikkate alınarak yapılan sınıflandırmaya göre sistem mimarisi türleri ve seçilen pilot bölgenin özellikleri üçüncü bölümde ele alınmaktadır. Sonrasında, otonom sistemin güvenilirlik endekslerine olan etkisi, seçilen pilot bölgede 2017 yılında gerçekleşen kesinti bilgilerinden elde edilen bulgular kullanılarak ortaya koyulmaktadır. Kesinti bilgileri, SEDAŞ'ın internet sayfasında yer alan Bilgi Danışma bölümündeki kayıtlardan ulaşılmıştır.

\section{Kendi Kendini İyileştiren Şebekede Arıza Yönetim Süreci}

Kendi kendini iyileştiren şebeke konsepti, temel olarak ak1llı elektronik cihazlar, uzaktan kontrol edilebilir kesiciler/ayırıcılar, otonom restorasyon algoritmalarını yürüten işlemciler ve isteğe bağlı 
olarak haberleşme sistemlerinden oluşmaktadır. Bu konseptin ana amacı, dağıtım şebekesindeki arızaların hızlı ve insan müdahalesi olmadan tespit edilmesi, mümkün olan en dar alanda arızanın izole edilmesi ve mümkün olan maksimum sayıda tüketicinin enerji tedariğinin en kısa sürede yeniden sağlanmasıdır. Gelişmiş ölçüm, kumanda ve haberleşme sistemlerinin entegre edilmesiyle oluşturulan otonom özellikteki bu şebeke konseptinde, güç sistemi arızalarına karşı otomatik cevaplar üretilmektedir. Bir arıza durumunda, otonom sisteme ait çalışma evreleri; sistem tarafindan arıza noktasının tespit edilmesi, sistemin arızalı kısmını sağlıklı kısımdan ayırmak için arıza izolasyonu ve fiderin sağlıklı kısımlarını yeniden enerjilendirmek için restorasyon manevraları olarak ifade edilebilir.

Şekil 1'de, sistemin çalışma evreleri gösterilmiştir. İlk evredeki arıza yerinin tespiti, arıza gösterge cihazları veya koruma rölelerin çıkış kontakları üzerinden elde edilebilmektedir. Arıza yeri tespiti, sorunun kaynağını bulmak ve soruna özgü doğru çözümü geliştirmek bakımından kritik önem teşkil etmektedir. İkinci aşamada, arıza yeri tespit edildikten sonra bu noktaya en yakın kontrol edilebilir anahtarlama elemanları tespit edilerek bu elemanlara açma komutları gönderilmektedir. Devrede bulunan arızalı kısım, sistemin geri kalanından izole edildikten sonra alternatif kaynağa geçiş için tadiye noktasındaki kesiciye kapama komutu gönderilmektedir. Böylece, yük aktarımı hazırda bekleyen ikincil kaynağa doğru gerçekleştirilmektedir. Telemetri özelliğine sahip olmayan istasyonlarda, saha ekipleri tarafindan yapılan manuel manevralarda bahsedilen arıza izolasyonu ve yeniden enerjilendirme süresi bir saatin üzerine çıkmaktadır. Şebeke topolojisi, coğrafi kısıtlar, personel uygunluğu ve benzeri faktörlere göre değişkenlik gösteren bu süre boyunca aslında arıza bölgesi içerisinde yer almayan müşteriler enerjisiz kalabilmektedir. Son olarak, saha ekibi gerekli çalışmaları yapıp arızayı temizledikten sonra şebekenin optimum çalışma rejimine dönmesi için otonom sistem tarafindan anahtarlama komutları gönderilerek ideal topolojiye geri dönülmektedir.
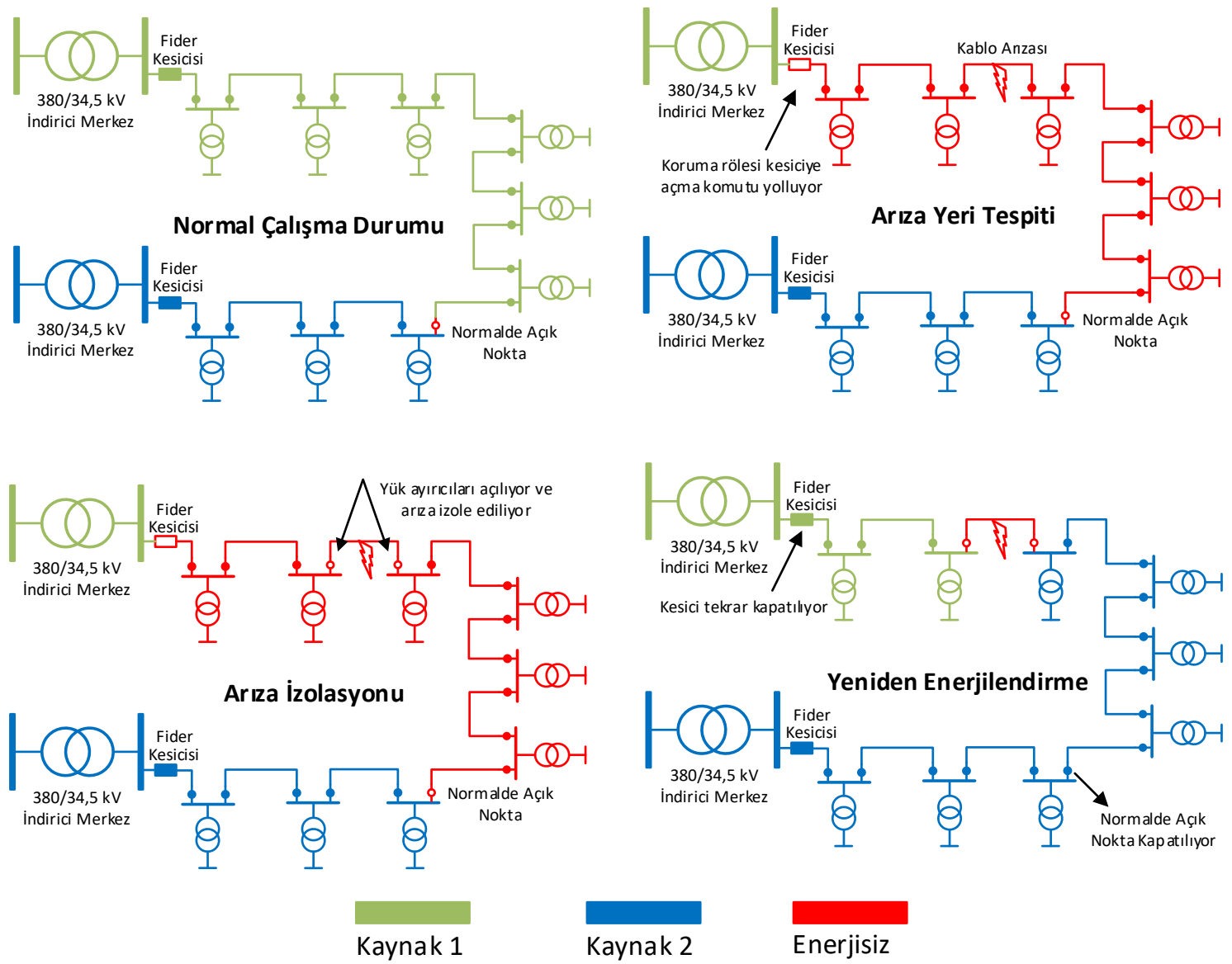

Şekil 1. Otonom sistem çalışma evreleri

Arıza yönetiminin otomatik yapılmasıla birlikte kesinti sürenin 1-5 dk mertebesine indirilebileceği ifade edilmektedir [7]. Şekil 2'de, konvansiyonel arıza yönetim sistemi ile otonom sistemin karşılaştırıldığ bir diyagram gösterilmiştir. 
Kendi kendini iyileştiren şebekelerin bir diğer önemli katkısı da arıza noktasını bulmak için saha ekibi tarafından manevra sayısını azaltmaktır. Konvansiyonel süreçlerde, saha ekipleri dağıtım merkezlerini gezerek anahtarlama noktalarında manevralar yapmakta, koruma sisteminin çalışıp çalışmama durumuna göre arıza noktasını tahmin etmeye çalışmaktadırlar. Ancak deneme-yanılma yöntemi olarak bilinen bu metotta aynı arızanın üzerine çok sayıda kapama yapılmakta, bu nedenle şebekeden geçen kısa devre sayısı çoğaltılmaktadır. Bu yüzden, birçok kez yüksek genlikli kısa devre akımlarına maruz kalan şebeke ekipmanlarının faydalı ömürleri kısalmaktadır. Otonom sistemlerde, deterministik arıza yeri tespiti yapıldığı için bu tür sistemlerin şebeke ekipmanlarının daha az zorlanmasını sağladığı söylenebilir.

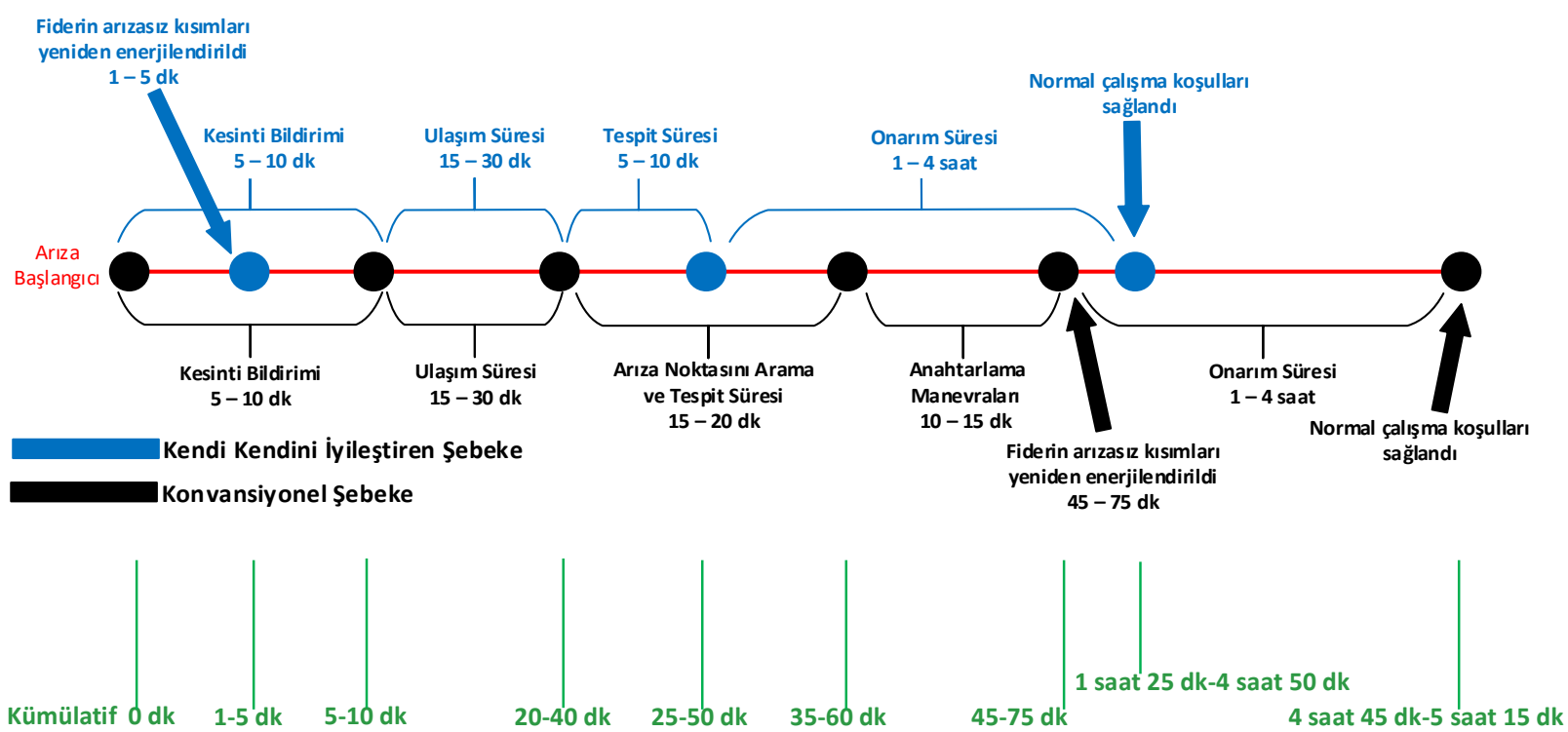

Şekil 2. Konvansiyonel arıza yönetim sistemi ve otonom sistemin kesinti süreleri

Bunlara ek olarak, saha ekiplerinin yorucu arıza yeri tespit işlemlerinde bulunmaması iş gücü optimizasyonunu sağlamaktadır. Dağıtım şebekesi acil durum ekiplerinin arıza sonrası faaliyetler yerine önleyici bakım süreçlerine yönlendirilmesine imkan sağlayacak bu iş modeli sayesinde, şebekede meydana gelen arıza sayısı düşürülebilecektir.

\section{Kendi Kendini İyileștiren Şebeke Özellikleri ve Bölge Seçimi}

\subsection{Sistem tasarımı}

Kendi kendini iyileştiren şebekelerde temel olarak üç farklı mimari kullanılmaktadır. Bunlar, saha ekipmanlarından toplanan verilerin değerlendirildiği ve bir anahtarlama dizisinin oluşturulduğu karar alma noktasının konumuna göre aşağıda sıralanmıştır:

a) Merkezi kontrol sistemi (Centralized Scheme)

b) Dağıtık veya yarı-merkezi kontrol sistemi (De-centralized Scheme)

c) Noktadan noktaya kontrol sistemi (Peer-Peer Scheme)

Merkezi kontrol sistemi mimarisinde, sistemde oluşan arıza, akıllı elektronik cihazlar (IED: Intelligent Electronic Device) tarafindan SCADA yazılımına bildirilmekte ve bu veriler direkt olarak DMS modülüne aktarılmaktadır. Sonrasında, DMS modülü toplanan verileri kullanarak, arızalı bölgenin restorasyonunu tamamlamak için analiz gerçekleştirmekte ve anahtarlama manevralarını oluşturmaktadır. Yapılan analiz, detaylı şebeke bağlantı modeli ile birlikte güç akışı algoritmalarına dayanmaktadır. Böylece restorasyon sonrasında şebekede akım taşıma kapasitesi ve gerilim genliğine dair limitlerde bir aşım oluşması engellenmektedir. Arıza izolasyonu ve yeniden enerjilendirme sürecinin yürütüldügü bölgenin yüklenme oranına göre restorasyon işlemlerinin karmaşılık düzeyi değişmektedir. Az yüklü bir bölgede yeniden enerjilendirme için birkaç manevra yeterli olur iken, yüklenme oranı limite yakın bölgelerde çok yönlü/çok katmanlı restorasyon işlemlerine ihtiyaç duyulmaktadır. Dağıtım merkezlerinden toplanan veriler arıza izolasyonu ve yeniden enerjilendirme 
merkezine noktadan-noktaya veya noktadan-çoklu noktaya haberleşme yöntemleriyle aktarılmaktadır. Merkezi sistem, her bir dağıtım merkezini ve o dağıtım merkezine bağlı akıllı elektronik cihazları sorguladıktan sonra restorasyon komutlarını yollamaktadır. Bu nedenle, tek bir haberleşme arızasında sistem düzeni inaktif konuma geçebilmektedir [8].

Dağıtık kontrol sistemi mimarisinde, sahada konumlandırılmış uzaktan yönetim birimi (RTU: Remote Terminal Unit) tarafından lojik işlemler yürütülmektedir. Master RTU analiz sonucunda elde ettiği anahtarlama prosedürlerini, sahadaki ilgili IED'lere ve ekipmanlara yollamaktadır. Böylece tek bir merkezi noktadan tüm işlemlerin yönetildiği yapı yerine, birden çok ana RTU'nun kendi bölgesinde arıza izolasyonu ve yeniden enerjilendirme sürecini yönettiği bir yapı oluşturulmaktadır. İşlemsel süreçler, dağıtım veya indirici merkezlerde yürütüldüğ̈̈ için merkezi kontrol sistemi ile karşılaştırıldığında saha ekipmanlarına olan haberleşme mesafeleri kısaltılabilmektedir. Dağıtık kontrol sistemi mimarilerinde yalnızca hat başında koruma yapılmakta ise arıza durumlarında önemli miktarda yük devre dışı bırakılmaktadır. Çözüm için sahada tekrar kapayıcıların ve ekstra koruma elemanlarının kullanılması durumunda, arıza izolasyonu ve yeniden enerjilendirme süreçleri başlatılmadan önce yerel koruma kararlarının ve aksiyonların tamamlanması gerekmektedir [8].

Noktadan noktaya kontrol sistemi mimarisinde, her bir IED arıza izolasyonu ve yeniden enerjilendirme algoritmalarını gerçekleştirebilmekte ve ana bileşen görevini alabilmektedir. Tasarımda, dağıtık ve merkezi sisteme kıyasla arıza izolasyonu ve yeniden enerjilendirme süreçlerinin tamamlanmaları daha kısa zamanlarda gerçekleşmektedir. Uygulamada bu süreler değişiklik göstermekle birlikte, genellikle dakikalar mertebesinden ziyade saniyeler mertebesinde otonom restorasyon süreci tamamlanmaktadır. Trafo merkezleri arasındaki haberleşme, fider RTU'ları ile sağlanabildiği gibi lojik programlama özelliği bulunan sayısal koruma röleleri üzerinden de sağlanabilmektedir. Özellikle, ethernet ve fiber optik teknolojilerinin gelişmesiyle önem kazanmış olan noktadan noktaya haberleşme mimarisi, 2003 yılında IEC 61850 protokolünün tanımlanmasıyla birlikte yaygınlaşmaya başlamışır [9].

Kendi kendini iyileştiren şebeke tasarımları, sistem yapısına özgü olarak yukarıda belirtildiği biçimde birtakım avantajları ve dezavantajları barındırmaktadır. Arıza izolasyonu ve yeniden enerjilendirme çalışmalarında şebeke tasarımı seçimi öncelik teşkil etmektedir. Bu seçime kılavuz olması açısından Tablo 1'de merkezi, dağıtık ve noktadan noktaya kontrol topolojileri karşılaştırmalı olarak verilmiştir.

Tablo 1. Sistem tasarımlarının karşılaştırılması

\begin{tabular}{llll}
\hline Mimari Niteliği & \multirow{2}{*}{ Merkezi } & Dağıtık & Noktadan \\
Noktaya
\end{tabular}

\subsection{Pilot uygulama}

SEDAŞ sorumluluk alanında bulunan ve yaklaşık 20.000 müşterinin bulunduğu Yahyakaptan bölgesi, pilot uygulama noktası olarak belirlenmiştir. Bölge, SEDAŞ SCADA sistemi tarafından izlenen Türkiye Elektrik İletim A.Ş.'ye (TEİAŞ) ait dört adet indirici trafo merkezi tarafindan beslenmektedir. Bu alanda SCADA sistemi ile izlenip kontrol edilecek toplam 67 adet dağıtım merkezi bulunmaktadır. Ayrıca, Kocaeli ilinin merkezi bir noktası olan bu alanda kaymakamlık binası, polis merkezi, hastane, telekomünikasyon santrali ve spor kompleksleri gibi stratejik öneme sahip kritik yükler bulunmaktadır.

Pilot alanda, yer altı ve havai hatların birlikte kullanıldığ 1 açık ring ve radyal fider şebeke topolojileri bulunmaktadır. Uygulama çalışmalarına geçilmeden önce yapılanlar aşağıda özetlenmiştir: Şebekenin optimum çalışma rejimi ve buna uygun olarak sistem topolojisi ve açı noktaları belirlenmiştir. 
a) Haberleşme bulunmayan stratejik istasyonlara telemetri tesis edilmesi planlanmıştır.

b) Modelleme çalışmaları yürütülmüş ve pilot şebeke bilgisayar ortamına aktarılmıştır.

c) Arıza senaryoları ve otonom anahtarlama dizileri çıkarılmıştır.

d) Her bir senaryo için gerilim düşümü, akım taşıma kapasitesi ve koruma sistemi incelemeleri yapılmıştır.

Sistem ihtiyaçları ve çalışma alanı belirlendikten sonra pilot uygulama için yarı-merkezi kontrol sistemi mimarisinde karar kılınmış ve aşağıda listelenen sistem/donanım gereksinimleri tespit edilmiştir:

a) Otonom restorasyon senaryolarının yürütüleceği ana kontrolör,

b) Saha cihazlarından veri toplamak ve komutları iletmek için RTU'lar,

c) Motorlu kesiciler,

d) Ölçü için akım ve gerilim transformatörleri,

e) Arıza algılama ve adaptif koruma için sayısal koruma röleleri,

f) Yer problemi bulunan kapalı şalt hücreleri için kapasitif/rezistif gerilim bölücüler,

g) Haberleşme alt yapısı için gerekli modem ve ethernet switch'ler.

Sistem, arıza izolasyonu ve yeniden enerjilendirme görevini yerine getirebilmek için dağıtım merkezlerini gerçek zamanlı olarak izlemektedir. Bu amaçla, kullanılmakta olan akıllı elektronik cihazlara her bir kesinti senaryosuna göre bir grup koruma değişim sinyali ana kontrolör tarafindan gönderilmektedir. Koruma grubu ayarları, pilot bölgenin kısa devre analizi sonuçlarına göre önceden tanımlanmaktadır. Ayrıca, şebeke topolojisi ana kontrolöre önceden tanımlandığından arıza izolasyonu ve yeniden enerjilendirme algoritmasının yürütülmesinden sonra sistemdeki yük akışı yönü normal çalışma koşulları durumundaki ile aynı olmaktadır.

\section{Bulgular}

Pilot bölgede uygulanacak otonom anahtarlama sinyal prosedürleri farklı arıza durumları için üretilmektedir. Bu prosedürler, ayrıca bir yazılım kullanılarak yük akışı ve kısa devre analizleri ile doğrulanmaktadır. Bölgedeki trafo merkezlerinden senelik bazda elde edilen akım ölçümleri bir eşzamanlılık faktörü ile değerlendirilip pilot bölgenin maksimum talep gücü hesaplanmaktadır. Analiz sonuçlarına göre, aşırı yüklenme durumunda primer ring hatlarda bir aşırı yüklenme oluşmamaktadır. İndirici trafo merkezlerinde de aşırı yüklenme görülmediği gibi, her bir arıza senaryosu için uygun bir anahtarlama prosedürü üretilebilmektedir.

Arıza izolasyonu ve yeniden enerjilendirme sisteminin kesinti süresine olan etkisini değerlendirebilmek için gerçek verilerin ve bir kısım varsayımların kullanıldığ 1 bir hesaplama yapılmıştır. Ortalama kesinti süresi ve her bir fiderdeki kesinti sayısı SCADA/DMS-OMS'den temin edilmiştir. Her bir fiderdeki tüketici sayısı da birbirlerine entegre edilmiş olan SCADA/DMS-OMS, Coğrafi Bilgi Sistemi (GIS) ve Müşteri Bilgi Sistemi ile bilinmektedir.

Mevcut durumda geleneksel SAIDI [10]:

$$
S A I D I=\frac{\sum\left(r_{i} * N_{i}\right)}{N_{T}}
$$

olarak bilinmektedir. Burada;

$r_{i}$ : yeniden enerjilendirme süresini (dakika),

$N_{i}$ : kesintiye maruz kalan toplam tüketici sayısını,

$N_{T}$ : toplam tüketici sayısını ifade etmektedir.

Arızaların \%80'inin geçici olduğu varsayımıyla, pilot bölgedeki tüketici başına düşen kesinti süresinde sağlanan iyileşme hesaplanmıştır [6,11]. Pilot bölgedeki çalışma sonrası SAIDI restorasyon değerini belirlemek için aşağıdaki formül kullanılmıştır.

$$
S A I D I_{\text {restorasyon }}=\frac{\sum\left(r_{i} * N_{i} *(1-k)\right)+\sum\left(r_{r} * N_{i} * k\right)}{N_{T}}
$$

Burada;

$k$ : restorasyon fonksiyonlarından fayda sağlayan kullanıcı sayısı

$r_{r}: 3 \mathrm{dk}$ (hedeflenen) 
Tablo 2. Pilot bölge için 2017 yılındaki kesinti bilgileri

\begin{tabular}{lcc}
\hline $\begin{array}{c}\text { Toplam Süre } \\
\text { (dakika) }\end{array}$ & $\begin{array}{c}\text { Fider başına ortalama } \\
\text { müşteri sayısı (adet) }\end{array}$ & $\begin{array}{c}\text { Müşterinin maruz kaldığı } \\
\text { kesinti süresi (dakika) }\end{array}$ \\
\hline 358.892 & 5.929 & 61 \\
3.510 .716 & 26.547 & 132 \\
1.782 .963 & 16.021 & 111 \\
1.179 .200 & 3.947 & 299 \\
358.378 & 1.839 & 195 \\
8.467 & 155 & 55 \\
26 & 1 & 26 \\
3.868 .544 & 6.366 & 608 \\
1.817 .259 & 7.449 & 244 \\
40.520 & 1.219 & 33 \\
11.081 & 548 & 20 \\
2.184 .673 & 5.569 & 392 \\
378.000 & 6.965 & 54 \\
42.237 & 7.184 & 6 \\
756.911 & 9.354 & 81 \\
634.142 & 24.950 & 25 \\
571.526 & 5.351 & 107 \\
704.783 & 21.326 & 33 \\
\hline
\end{tabular}

Tablo 3. Otonom sistem uygulandıktan sonra pilot bölgedeki oluşacak kesinti bilgileri

\begin{tabular}{|c|c|c|c|c|}
\hline Faydalanan & Faydalanamayan & Faydalanan & Toplam & Müşterinin maruz kaldığ \\
\hline müşteri sayısı & müşteri sayısı & kesinti süresi & kesinti süresi & kesinti süresi \\
\hline 4.743 & 1.186 & 14.229 & 86.575 & 15 \\
\hline 21.238 & 5.309 & 63.714 & 764.502 & 29 \\
\hline 12.817 & 3.204 & 38.451 & 394.095 & 25 \\
\hline 3.158 & 789 & 9.474 & 245.385 & 62 \\
\hline 1.471 & 368 & 4.413 & 76.173 & 41 \\
\hline 124 & 31 & 372 & 2.077 & 13 \\
\hline 1 & 0 & 3 & 3 & 3 \\
\hline 5.093 & 1.273 & 15.279 & 789.263 & 124 \\
\hline 5.959 & 1.490 & 17.877 & 381.437 & 51 \\
\hline 975 & 244 & 2.925 & 10.977 & 9 \\
\hline 438 & 110 & 1.314 & 3.514 & 6 \\
\hline 4.455 & 1.114 & 13.365 & 450.053 & 81 \\
\hline 5.572 & 1.393 & 16.716 & 91.938 & 13 \\
\hline 5.747 & 1.437 & 17.241 & 25.863 & 4 \\
\hline 7.483 & 1.871 & 22.449 & 174.000 & 19 \\
\hline 19.960 & 4.990 & 59.880 & 184.630 & 7 \\
\hline 4.281 & 1.070 & 12.843 & 127.333 & 24 \\
\hline 17.061 & 4.265 & 51.183 & 191.928 & 9 \\
\hline
\end{tabular}

Tablo 2, SEDAȘ'ın 2017 y1lı için internet sitesinde paylaştığı kesinti bilgilerinden sadece pilot bölge ile ilgili verileri göstermektedir [12]. 2017 yılı verilerinden elde edilen SAIDI yaklaşık $121 \mathrm{dk}$ ve ortalama kesinti sıklığ 1 endeksi (SAIFI) 6 olarak belirlenmiştir. Arıza izolasyonu ve yeniden enerjilendirme sistemi ile hedef, anahtarlama işlemlerinin 3 dk'nın altında bir sürede tamamlanmasıdır. Pilot bölgedeki çalışma sonrası elde edilen veriler ise Tablo 3'te gösterilmektedir. Restorasyon çalışması sonrası SAIDI değeri $27 \mathrm{dk}$ olarak hesaplanmıştır.

\section{Sonuç ve Öneriler}

Dağıtım şebekelerindeki tedarik sürekliliğini iyileştirme motivasyonunun düzenleyici kurumlar tarafından artırılması ile kendi kendini iyileştiren şebekelerin hem ulusal hem de uluslararası çapta yaygınlaşması beklenmektedir. Kendi kendini iyileştiren şebeke mimarileri, tasarım ve analiz 
çalışmalarına dair bilgi birikiminin oluşturulmasıyla pilot uygulamaların önünün açılacağı öngörülmektedir.

SEDAŞ, bahsedilen konsepti kanttlamak, müşteri memnuniyeti ile tedarik sürekliliğini daha iyi hale getirmek ve gelişmiş dağıtım otomasyon sistemleri alanında deneyim sahibi olmak için Türkiye'de yapılacak ilk otonom şebeke projesine öncülük etmiş̧ir. Bu çalışma, kendi kendini iyileştiren şebeke mimarilerinin karşılaştırılmasını, gerçek şebeke bilgileri kullanılarak yapılan simülasyon tabanlı bir durum analizini ve önerilen ariza izolasyonu/yeniden enerjilendirme sisteminin ortalama kesinti süresine olan etkisini kapsamaktadır. Bu amaçla, Kocaeli'nin Yahyakaptan bölgesinde yaklaşık 20000 müşterinin bulunduğu bir alan, pilot bölge olarak seçilmiştir. Kaymakamlık binası, polis merkezi, hastane, telekomünikasyon santrali ve spor kompleksleri gibi stratejik öneme sahip kritik yükler ile yer altı ve havai hatların birlikte kullanıldığı açık ring ve radyal fider şebeke topolojilerinin bu alanda bulunması bölgenin pilot uygulamanın yapılacağı alan olarak seçilmesinde etkili olmuştur. Sistemin devreye girmesinin ardından yapılan tahminlerde müşteri başına ortalama kesinti süresinin $27 \mathrm{dk}$ olarak belirlenmesi ile bu sürenin yaklaşı \%78 düşeceği öngörülmektedir. Özellikle, kesintilerle en fazla karşılaşılan yaz aylarında bu sistemin daha fazla devreye girip çıkarak elektrik enerjisine ihtiyacın çok olduğu dönemlerde katkıda bulunacağı düşünülmektedir.

Kendi kendini iyileştiren şebekeler ile birlikte arıza yönetim süreçlerinden insan faktörünün çıkarılması sonucunda müşterilere hızlı enerji verebilecek ve kesintilerin getirdiği sosyal ve finansal kayıplar minimize edilecektir. Ancak, insan faktörünün devreden çıkarılmasıyla beraber İş Sağlı̆̆ 1 ve Güvenliği (İSG) süreçlerinin yenilenmesi ve bu çalışma tipi için gerekli güvenlik aksiyonlarının planlanması gerekecektir. Bu güvenlik aksiyonlarının, hem yazılımsal kilitlemeler hem otomasyon noktalarındaki kilitlemeler hem de saha prosedürleri başlıklarında ele alınması önerilmektedir.

$\mathrm{Bu}$ konu ile ilgili bir başka kısıt ise personel yeterliliği olarak değerlendirilmektedir. Sistemin ayakta kalmasını sağlamak, olası problemleri çözmek ve yeni şebeke bileşenlerini sisteme entegre etmek için kalifiye otomasyon mühendislerine ve teknisyenlere ihtiyaç duyulmaktadır. Dolayısıyla kendi kendini iyileştiren şebekeye dair uygulamalı eğitimlerin düzenlenmesi ve personel uzmanlık seviyesinin artırılması tavsiye edilmektedir.

\section{Teşekkür}

$\mathrm{Bu}$ çalışma, EPDK tarafindan desteklenen "Uygun Anahtarlama Operasyonları ile Kendi Kendini İyileştiren (Self-Healing) Şebekeye Geçiş" projesi kapsamında gerçekleştirilmiştir (Proje no: 01-17-15).

\section{Yazarların Katkısı}

Çalışmada tüm yazarlar eşit oranda katkı sunmuştur.

\section{Çıkar Çatışması Beyanı}

Yazarlar arasında herhangi bir çıkar çatışması bulunmamaktadır.

\section{Araştırma ve Yayın Etiği Beyanı}

Yapılan çalışmada, araştırma ve yayın etiğine uyulmuştur.

\section{Kaynaklar}

[1] Coster E., Oirsouw P.V., Lava J., Parabirsing E. 2013. Automated analysis of distribution grid protective schemes. 22nd International Conf. and Exhibition on Electricity Distribution, pp.1-4, Stockholm.

[2] Coster E., Kerstens W.C.M., Schroedel O. 2014. Implementation of an automatic FLIR-scheme in a $20 \mathrm{kV}$ distribution grid. 12th IET International Conf. on Developments in Power System Protection, pp.1-6, Copenhagen.

[3] Marti J., Gutierrez J., Gabriel E., Richter C., Beiglboeck E., Moise V. 2011. Automatic Isolation and Restoration. 11th Electric Power Center Conf., Altea, Spain. 
[4] Tarhuni N.G., Elkalashy N.I., Kawady T.A., Lehtonen M. 2015. Autonomous control strategy for fault management in distribution networks, Electric Power System Research, 12: 252-259.

[5] U.S. Department of Energy. 2014. Fault location, isolation, and service restoration technologies reduce outage impact and duration, Smart Grid Investment Grant Program, USA.

[6] Elkadeem M.R., Alaam M.A., Azmy A.M. 2016. Optimal automation level for reliability improvement and self-healing MV distribution networks, 18th International Middle East Power Systems Conference, pp.206-213, Cairo.

[7] Agüero J.R. 2012. Appying self-healing schemes to modern power distribution systems, IEEE Power and Energy Society General Meeting, pp.1-4, San Diego, CA.

[8] Tutvedt K.A., Seguin R., Kjolle G., Simonsen S., Hermansen T.S., Myhr I. 2017. Smart fault handling in medium-voltage distribution grids, 24th International Conf. \&Exhibition on Electricity Distribution, pp.1471-1474, Glasgow.

[9] Yip T., Wang J., Xu B., Fan K., Li T. 2017. Fast self-healing control of faults in MV networks using distributed intelligence. 24th International Conf. \&Exhibition on Electricity Distribution, Glasgow, Scotland, pp.1131-1133.

[10] IEEE Power Engineering Society IEEE 1366. 2012. IEEE Guide for Electric Power Distribution Reliability Indices.

[11] Hasançebi G., Yeğin E.M., Karaarslan K. 2018. Status determination of fault characteristics in medium voltage power distribution system, Journal of Engineering Research and Applied Science, 7 (2): 980-983.

[12] SEDAŞ. 2018. https://www.sedas.com/tr-tr/Bilgi_Danisma/Pages/Tablo1.aspx (Erişim Tarihi: 02.03.2019) 